Document downloaded from:

http://hdl.handle.net/10251/101679

This paper must be cited as:

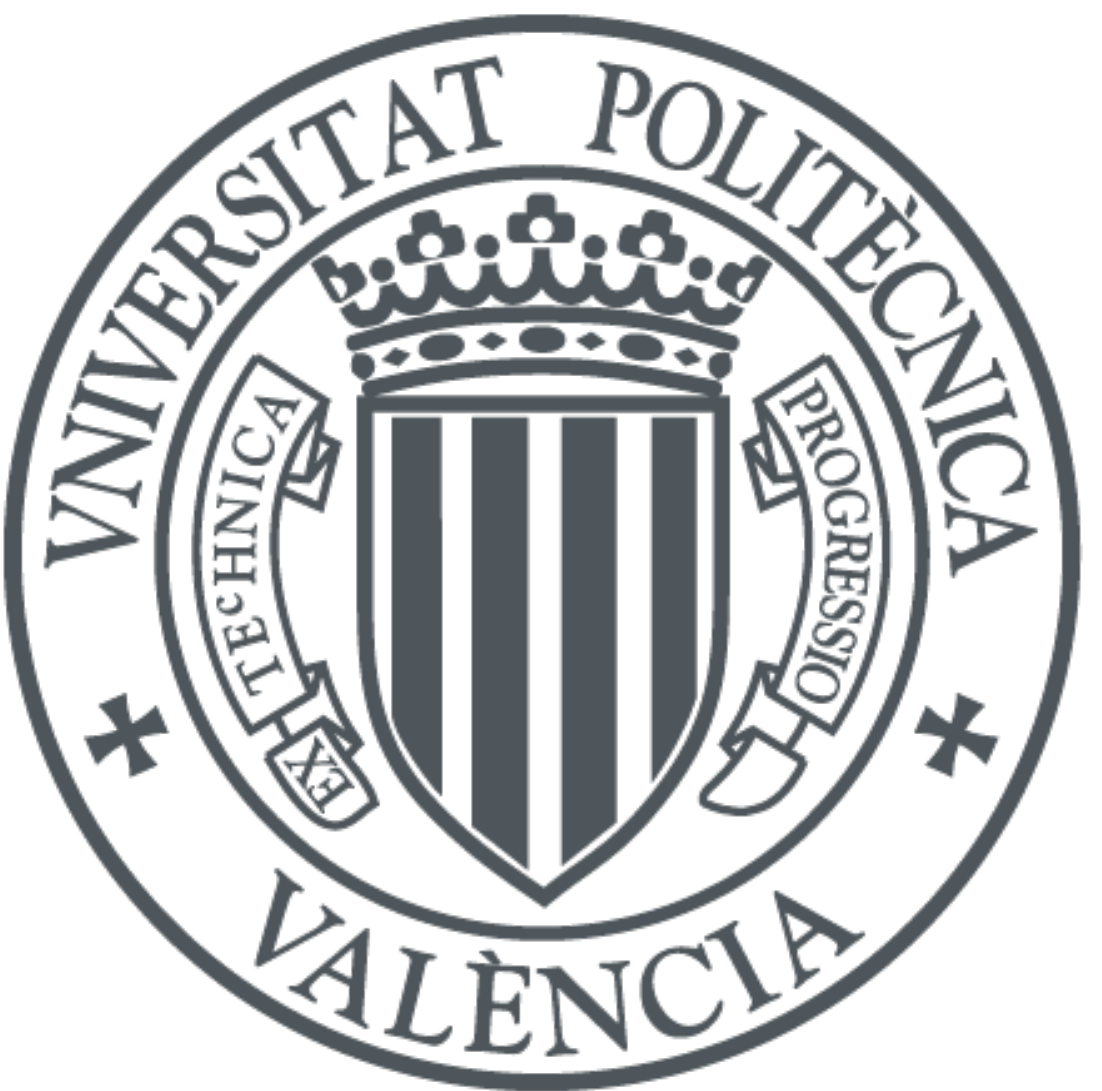

The final publication is available at

https://doi.org/10.1016/j.polymdegradstab.2015.04.015

Copyright Elsevier

Additional Information 


\title{
Effects of hydroxyapatite filler on long-term hydrolytic degradation of PLLA/PCL porous scaffolds
}

\author{
Joaquin Rodenas Rochina ${ }^{2}$, Ana Vidaurre ${ }^{1,2^{*}}$, Isabel Castilla Cortazár ${ }^{2}$, Myriam Lebourg ${ }^{1,2}$ \\ ${ }^{1}$ CIBER de Bioingeniería, Biomateriales y Nanomedicina (CIBER-BBN) \\ ${ }^{2}$ Center for Biomaterials and Tissue Engineering (CBIT).
}

\begin{abstract}
Poly(L-lactic acid)(PLLA)/poly(ع-caprolactone)(PCL)/hydroxyapatite(HAp) composites appear as promising materials for healing large bone defects. Highly porous PLLA/PCL scaffolds, 80/20, $20 / 80$ weight ratios, porosity $>85 \%$, were prepared by a dual technique of freeze extraction and porogen leaching, with and without HAp. A double pore structure was obtained, with interconnected macroporosity together with interconnected microporosity. Elastic modulus and yield strength of as-synthesized scaffolds were higher for PLLA rich blends and including the inorganic phase does not lead to a mechanical strengthening in these materials. Subsequent long-term ( 78 weeks $=1.5$ years) hydrolytic degradation behavior was investigated in terms of the samples' mechanical properties, molecular weight $\left(\mathrm{M}_{\mathrm{w}}\right)$, mass changes, thermal characteristics, X-ray Diffraction and Thermogravimetric Analysis. Elastic modulus and yield strength of as-synthesized scaffolds were higher for PLLA rich blends and including the inorganic phase does not lead to a mechanical strengthening in these materials. Nevertheless, after 30 weeks of degradation, PLLA rich scaffolds lost more than half of their strength and rigidity. On the contrary, the densification modulus of the PLLA based blends increased with degradation time, whereas PCL-based blends had a relatively constant densification modulus. PCL-based samples showed lower hydrolysis coefficients $k$ than PLLA-based samples, as expected from the higher density of ester bonds in the latter. Interestingly, although including HAp leads to a lower hydrolysis coefficient $k$ in PCL rich samples, it increases $k$ in the PLLAbased sample, which is consistent with the other results obtained.
\end{abstract}

Keywords - hydroxyapatite, Poly(I-lactic acid), Poly( $\varepsilon$-caprolactone), Polyester blends, long term hydrolytic degradation, hydrolysis coefficient

\footnotetext{
* Corresponding author. Address: Center for Biomaterials and Tissue Engineering (CBIT), Universitat Politècnica de València, Camino de Vera s/n, 46022 Valencia, Spain. Tel: +34 96387 7007, ext. 88934; Fax: +34 96387 7276. E-mail address: vidaurre@fis.upv.es (Ana Vidaurre)
} 


\section{Introduction}

The controllability of biomaterials' physical properties is crucial for both investigating cellmaterial interactions and developing suitable materials for the different needs in tissue engineering applications [1]. One common approach is to implant a biodegradable scaffold for tissue ingrowth, with the purpose of stimulating and directing tissue formation in situ [2-4].

To fulfill the diverse needs in tissue engineering, various materials have been exploited as scaffolds for tissue regeneration. Biodegradability is generally required for a tissue engineering scaffold material, and the degradation rate also needs to match the neo tissue formation rate to ideally serve the template purpose [5]. Linear aliphatic polyesters are frequently used as polymers for scaffold fabrication because of their wide range of biodegradability, in addition to their well accepted biocompatibility [6-9]. Among aliphatic polyesters poly(L-lactide) (PLLA)[10$16]$ and poly( $\varepsilon$-caprolactone) (PCL) $[12,15,17,18]$ are two well-known representatives, whose syntheses and properties have been extensively studied. These synthetic materials have been shown to be biocompatible and degrade into non-toxic components with a controllable degradation rate in vivo [19].

The incorporation of hydroxyapatite (HAp) [20] into the polymer matrix produces a hybrid/composite material. Many research studies for artificial bone production have been carried out using nanocomposites containing Hydroxyapatite (HAp) particles with polymer matrices [21]. It has been proven that the nano-HA is superior to conventional micro HA for promoting osteoblast adhesion, differentiation and proliferation, osteointegration, and deposition of calcium-containing minerals on its surface, which leads to enhanced formation of new bone tissue within a short period [22]. A composite material would improve biocompatibility and hard tissue integration due to the fact that ceramic particles, which are embedded into the polymer matrix, allow increased initial flash spread of serum proteins, compared to the more hydrophobic polymer surface [23]. Composites made of collagen-PLLAhydroxyapatite are also being increasingly considered for use as scaffold materials for bone tissue engineering [24]. Hydroxyapatite/poly(L-lactic acid) composite scaffold showed the presence of molecular interactions and chemical linkages between HAp particles and the PLLA matrix, affecting the interfacial behavior and mechanical properties of the HAp/PLLA composites $[25,26]$. These inorganic fillers allow the desired degradation and resorption kinetics of the polymer matrix to be tailored. Hutmacher's group has evaluated and patented the parameters necessary to process PCL and PCL composites by Fused Deposition Modelling (FDM) [27]. Materials with a hybrid structure in PCL-HAp scaffold resulting from biomimetic apatite growth have also been developed [28, 29].

Biodegradable synthetic polymers such as PLLA and PCL and HAp bioactive ceramics have been proposed to manufacture porous multi-layer scaffolds in order to simulate the mechanical properties of the layered tissues of articular joints [30]. Guarino and Ambrosio reported on the synergic effect of PLA and calcium phosphate reinforcement of PCL composites [31]. Charles et al., in an attempt to improve the mechanical properties of HAp/PLLA/PCL composites, incorporate PLLA as fiber reinforcement instead of melt or solvent cast matrix [32].

While a considerable number of in vitro and in vivo degradation studies exist for biodegradable polymers (such as PLLA, PCL) and bioactive ceramics alone, in vitro degradation studies for polymer/ceramic composites only began a few years ago [33,34]. There is a lack of current understanding in the literature regarding the long-term in vitro and in vivo characterization of 
porous scaffold composites, specifically regarding the long-term effect of the incorporation of inorganic bioactive phases on degradation [35].

In the present study PLLA/PCL scaffolds, at $80 / 20,20 / 80$ weight ratios, were prepared by a dual technique of freeze extraction and porogen leaching, with and without HAp (20\% w/w), with the aim of evaluating the effect of HAp on long term hydrolytic degradation. The hypothesis to be tested was that including an inorganic phase could modulate the degradation mechanisms involved and that the presence of inorganic filler (HAp) could affect both phases (PCL and PLLA) differently. The hydrolytic degradation in phosphate-buffered solution was carried out at $37{ }^{\circ} \mathrm{C}$, with orbital shaking, for a period of up to 78 weeks. The scaffolds were characterized by Scanning Electron Microscopy (SEM), gravimetric measurements, Gel Permeation Chromatography (GPC), Differential Scanning Calorimetry (DSC), X-ray Diffraction, Thermogravimetric Analysis and Compression Tests.

\section{Materials and Methods}

\section{Materials}

PLLA ( $M w=124,000$; with a 99.6\% L-lactic acid sequences) was purchased from Cargill-Dow; $\mathrm{PCL}(\mathrm{Mw}=48,000)$ was purchased from Polysciences; 1.4-Dioxane and $98 \%$ pure ethanol from Scharlab. All the solvents acquired had the highest degree of purity. HAp particles (diameter 100nm) were purchased from Sigma Aldrich. Acrylic microspheres (diameter $200 \mu \mathrm{m}$ ) were purchased from Lucite International.

\section{Scaffold preparation}

The scaffolds were prepared by a dual technique of freeze extraction combined with porogen leaching [36] of 15 weight \% solutions of PCL and PLLA in dioxane. In order to avoid the blend ratio where phases are cocontinuous (which in previous experiments, [37], has proven to lead to a very weak structure when produced as a macroporous scaffold), PLLA/PCL weight ratios of $80 / 20$ and 20/80 were used. Hydroxyapatite (Sigma Alrich, particle size $<100 \mathrm{~nm}$ ), 20\% w/w with respect to polymer weight, was dispersed in the solvent before adding the polymer. Polymer solutions were mixed 1:1 w/w with acrylic microspheres (Lucite International) in Teflon plates and frozen in liquid nitrogen. Only one disc of diameter $60 \mathrm{~mm}$ was prepared from each composition. The disks were then immersed in ethanol at $-20^{\circ} \mathrm{C}$ for two days to remove the dioxane, during which time the ethanol was changed three times. Circular samples $6 \mathrm{~mm}$ in diameter were stamped out of the disks; height was standardized to $3.5 \mathrm{~mm}$. The porogen was then leached with ethanol at ambient temperature; the scaffolds were washed for 10 days until no further acrylic traces were found in the washing solvent. The samples were vacuum-dried for at least three days and stored in a dry environment with desiccant vessels until the experiments were performed. The different compositions of the polymeric composite scaffolds are named as follow: PCLb= PCL/PLLA (80/20); PLLAb= PCL/PLLA (20/80); PCLb-H= PCL/PLLA(80/20)+20\% HAp; PLLAb-H= PCL/PLLA $(20 / 80)+20 \% H A p$, indicating the main component of the blend and the presence or absence of hydroxyapatite.

\section{Degradation studies}


In the degradation studies, phosphate buffer was used instead of phosphate saline buffer in order to avoid salt precipitation onto the samples. In a previous study it was proved that the degradation rate of polyesters was very similar using either water or buffer [38, 39], as long as $\mathrm{pH}$ is kept constant. The degradation study was conducted using phosphate buffer $(3,12 \mathrm{~g}$ $\mathrm{NaH}_{2} \mathrm{PO}_{4}$ and $28.66 \mathrm{~g}$ de $\mathrm{Na}_{2} \mathrm{HPO}_{4}$ per liter, $\mathrm{pH}=7.4$ ) and $0.02 \% \mathrm{NaN}_{3}$ as an antibacterial and antimicrobial agent. The ratio of sample weight to buffer volume was $0.5 \% \mathrm{w} / \mathrm{v}$; $\sim 10 \mathrm{mg}$ samples were incubated in $2 \mathrm{ml}$ buffer after thorough pre-wetting of the porous samples in order to subdue the material's hydrophobicity and to force the aqueous medium into the pores. The degradation medium was changed every two weeks. The sample vials were incubated in a water bath at $37^{\circ} \mathrm{C}$ with orbital shaking. 7 samples for each degradation time were cut from the same scaffold.

\section{Electron scanning microscopy and energy dispersion spectroscopy}

In order to observe the internal morphology, the scaffolds were fractured in liquid nitrogen, mounted on copper stubs and gold sputtered. The samples were observed with a JEOL JSM6300 scanning microscope equipped with energy dispersion spectroscopy (EDS) under an acceleration tension of $10 \mathrm{kV}$.

\section{Weight, pH and porosity measurement}

Weight loss was determined by weighing the scaffolds before and after degradation. After different periods of time the scaffolds were removed from the solution, washed with distilled water, weighed wet and allowed to dry to constant weight. The reported values are the average of 3 determinations of 5-7 replicates. A balance (Mettler Toledo) with a sensitivity of $0.01 \mathrm{mg}$ was used to weigh the samples. When dry, the samples were stored in a sealed container with desiccant vessels at $-80^{\circ} \mathrm{C}$ to prevent any further degradation. The $\mathrm{pH}$ measurements were carried out using a $\mathrm{pH}$ meter equipped with an $\mathrm{Ag} / \mathrm{AgCl}$ electrode. Porosity was measured by gravimetric means. The samples were weighed dry, filled with ethanol under vacuum, and subsequently weighed again. Porosity was calculated as the ratio of the volume of pores and the total volume of the scaffold according to Eq. (1)

$$
V_{\text {pore }}=\frac{m_{\text {wet }}-m_{\text {dry }}}{d_{\text {ethanol }}}
$$

where $m_{\text {wet }}$ and $m_{d r y}$ are the weights of the wet and dry samples, respectively, and $d_{\text {ethanol }}$ is the ethanol density.

\section{Differential Scanning Calorimetry}

DSC measurements were carried out in a Mettler Toledo 823e DSC on samples with a weight between $5-10 \mathrm{mg}$. A first heating scan at $10 \circ \mathrm{C} / \mathrm{min}$ from $0 \circ \mathrm{C}$ to $220^{\circ} \mathrm{C}$ enabled the structure of the sample to be characterized after degradation. After annealing at $220^{\circ} \mathrm{C}$ for three minutes and cooling at $10^{\circ} \mathrm{C} / \mathrm{min}$ to $0{ }^{\circ} \mathrm{C}$, a second heating scan at $10^{\circ} \mathrm{C} / \mathrm{min}$ was recorded to analyze the behavior after erasing the thermal history. The degrees of crystallinity were calculated for each phase of the blend assuming the melting heat for pure crystals of PLLA and PCL to be $\Delta H$ OPLLA=90.95 J/g [40] and $\Delta \mathrm{H} O P C L=136.1 \mathrm{~J} / \mathrm{g}$ [41] respectively.

\section{X-ray Diffraction}


X-ray diffraction spectra of the degraded samples were obtained on a Rigaku Ultima IV X-ray diffractometer, in the Bragg-Bentano configuration using the $\mathrm{K} \alpha$ radiation of a $\mathrm{Cu}$ anode. The samples were scanned from $2 \theta=10-50 \circ$ at a speed of $2 \% / \mathrm{min}$. Crystallite size was determined using the Debye-Scherrer equation [42].

$$
D=0.9 \frac{\lambda}{\beta \cos \theta}(2)
$$

where $D$ is the thickness of lamellar crystal, $\beta$ is the full-width at half-maximum (FWHM) of the diffraction peak in radians, $\lambda$ is the wavelength used, and $\theta$ is the angle between the incident ray and the scattering planes. The constant 0.9 in Eq. (2) depends to an extent on the symmetry of the crystal and has been discussed by several authors $[43,44]$.

\section{Gel permeation chromatography (GPC)}

The weight average molar mass of the samples was determined with a gel permeation chromatographer, GPC, at $30{ }^{\circ} \mathrm{C}$ using a Waters Breeze GPC system with a 1525 Binary HPLC pump (Waters Corporation, Milford, MA) equipped with a 2414 refractive index detector and Waters Styragel HR THF columns. THF was used as the eluent at a flow rate of $1 \mathrm{ml} / \mathrm{min}$. The calibration curve was prepared by using monodisperse polystyrene standards from Shodex (Showa Denko K.K., Kawasaki, Japan). The rate constant for hydrolysis, k, can be calculated from the evolution of the molecular weight with time [45]:

$$
\ln M_{n, t}=\ln M_{n, 0}-k t \quad \text { (3) }
$$

Where $M_{n, t}$ and $M_{n, 0}$ are the average molecular weight number at degradation time $t$ and at initial time, respectively

\section{Thermogravimetric Analysis}

The thermogravimetric analysis was performed in an SDT Q6000 from TA Instruments to determine the amount of different phases in the composite scaffolds as well as their evolution with degradation time. The samples were placed in a platinum pan and subjected to a heating scan from 50 to $700^{\circ} \mathrm{C}$ at $10^{\circ} \mathrm{C} / \mathrm{min}$ under nitrogen atmosphere. Mass was monitored as a function of temperature; the results were analyzed using the TA Analyzer software of the instrument. Degradation peaks of PLLA and PCL were determined using PLLA and PCL samples and the corresponding weight loss was ascribed either to the remaining PCL or PLLA phase. The solid residue at $700^{\circ} \mathrm{C}$ was ascribed to HAp and precipitated salts. The weight loss at $150 \circ \mathrm{C}$ is due to the moisture present in the sample in atmospheric conditions.

\section{Compression Tests}

Compression tests were performed using a Microtest universal testing machine with a $15 \mathrm{~N}$ load cell. A load ramp was applied at $1 \mathrm{~mm} / \mathrm{min}$ until a force of $14 \mathrm{~N}$ was reached. An elastic modulus of the scaffold was determined using a stress-strain representation. The method of calculating the curve interpretation and modulus was taken from ASTM D1621-04a standard "Compressive properties of rigid cellular plastics". The results are given as the average values of at least five measurements. 


\section{Results}

Initial characterization of the scaffolds

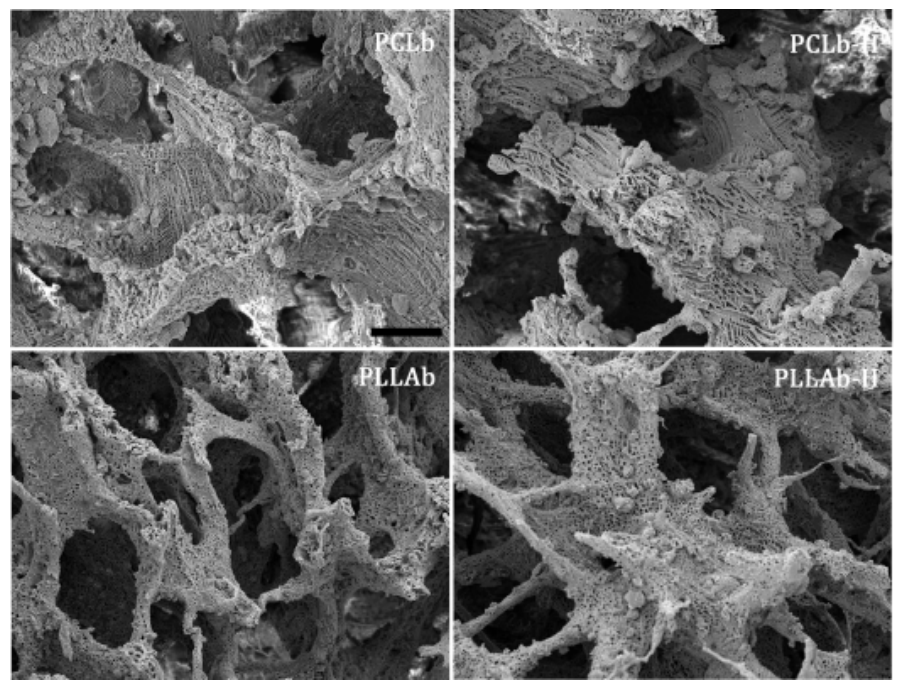

Figure 1. Microstructure of polyester scaffolds before degradation (bar size: $150 \mu \mathrm{m}$ )

All synthesized membranes appeared homogeneous and showed physical and mechanical integrity. As a result of the dual preparation process, a double pore structure was formed, as shown in Fig 1. Macropores measuring 300-400 $\mu \mathrm{m}$ were obtained from porogen leaching, whereas micropores $(1-10 \mu \mathrm{m})$ were produced by phase separation between solvent and polymer during nitrogen quenching and subsequent elimination of the dioxane phase. The overall morphologies of the scaffolds were similar, regardless of PCL/PLA ratio, although it was observed that PLLA rich samples tended to have thinner struts than PCL rich ones. The PLLA rich samples showed a higher starting porosity, around 90\%, in comparison with PCLb and PCLb-H scaffolds, whose porosity was around $86 \%$ (statistical analysis showed significant differences in porosity between all samples except for PLLA rich samples, PLLAb and PLLAbH). PCL and PLLA were phase separated, as proven by the fact that the glass transition temperature of $\mathrm{PCL}$ in the blend was independent of blend composition. Spherical domains of the minority phase were seen to be included inside the main phase; this phenomenon was more exacerbated for PCLb and PCLb-H. Including the inorganic phase did not modify the morphology of the scaffolds as scaffold structure was similar for both PCLb and PCLb-H on one hand and PLLAb and PLLAb-H on the other. Elemental analysis (data not shown) indicates that hydroxyapatite was homogeneously distributed along the scaffold, preferentially in the PLLA phase. Similar results were obtained in a previous study [36], in a PCL composite. Also, Mathieu et al. [46] have compared and optimized three methods for preparing a homogeneous blend of hydroxyapatite with a poly(L-lactic) acid.

\section{Weight loss, morphology and porosity}

The in vitro hydrolytic degradation of PCL/PLLA scaffolds, with and without HAp, using phosphate buffered solution at $37^{\circ} \mathrm{C}$ was carried on for a 78-week period. The weight loss and evolution of the composition, as determined by weighing and thermogravimetry, respectively, 
is shown in Fig 2. This type of visualization allows the total weight loss and the weight loss attributed to each phase to be presented simultaneously: PCL (Blue), PLLA (green) and inorganic content (red). According to figure 2 , at time $=0$, it seems that not all the HAp is incorporated. PLLA rich samples have incorporated $\sim 19 \%$, and PCL rich samples $\sim 14 \%$. Mineral loss could happen during freeze extraction, released with the solvent, or/and detached during the process of particle leaching.

The weight loss was most noticeable in the PLLA rich blend sample (PLLAb) and least noticeable in the PCL rich composite sample (PCLb-H). In the case of PCL rich blends (PCLb and PCLb-H), including HAp seemed to limit weight loss in the polymeric phase, while in the PLLA rich blends, (PLLAb and PLLAb-H) it leaded to an induction period of around 30 weeks, after which there was an increased loss of the polymeric phase. It was also observed that there was not inorganic weight loss during the degradation period. This could be attributed to salt deposition from the degradation medium. In fact, TGA data revealed the presence of small amounts of inorganic phase in degraded PCLb and PLLAb (less than 6\%), which had been confirmed by EDS (data not shown). This effect was more pronounced in samples containing HAp which could be acting as nucleation point. Capital letter on the top indicates significance $(p<0.05)$ compared to same material phase at day 0 is signaled as: $(A)$ PLLA, (B) PCL and (C) mineral particles.

In order to quantify the mass loss, the data in Table 1 shows the relative amount (with respect to $t_{0}$ ) of PCL or PLLA remaining at the end of degradation time. Introducing HAp leaded to a dramatic increase in PCL's remaining weight (more pronounced when PCL was the main phase, from $72 \%$ in PCLb to $96 \%$ in PCLb-H ). However, the PLLA's remaining weight decreased in PCL rich blends, from $43 \%$ in PCLb to $35 \%$ in PCLb-H whereas there was no significant difference in PLLA rich blends ( $31 \%$ in PLLAb and PLLAb-H).

No significant variations were found in $\mathrm{pH}$ during the entire degradation period, with values around $7.4 \pm 0.04$.

Figure 2. Evolution of sample weight and composition with time as determined by weighing and thermogravimetry. PCL (Blue), PLLA (green) and inorganic content (red). Error bars represent standard deviation, $N=7$. Significance $(p<0.05)$ compared to same material phase at day 0 is signaled as: $(A) P L L A,(B)$ $P C L$ and $(C)$ mineral particles. 
PCLb

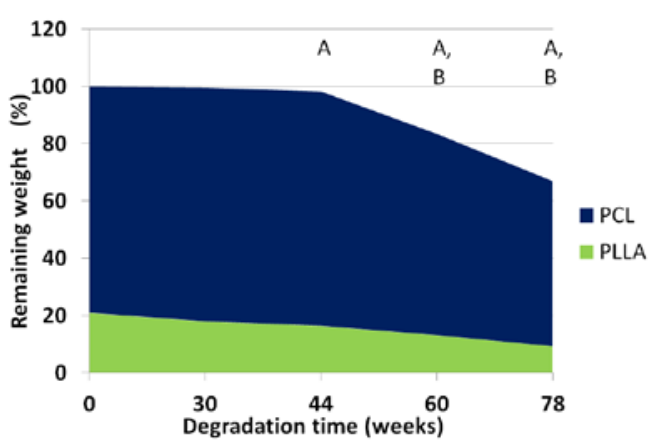

PCLb-H

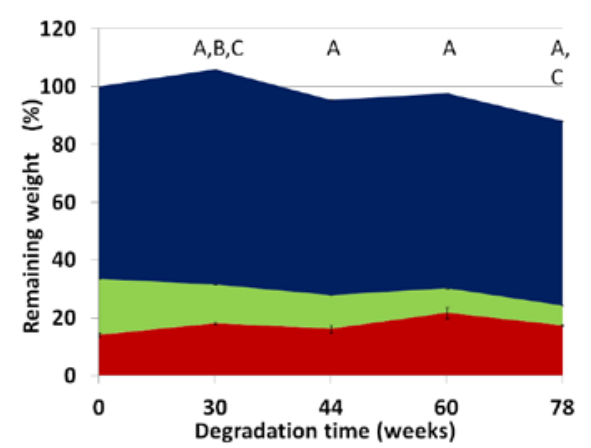

\section{PLLAb}

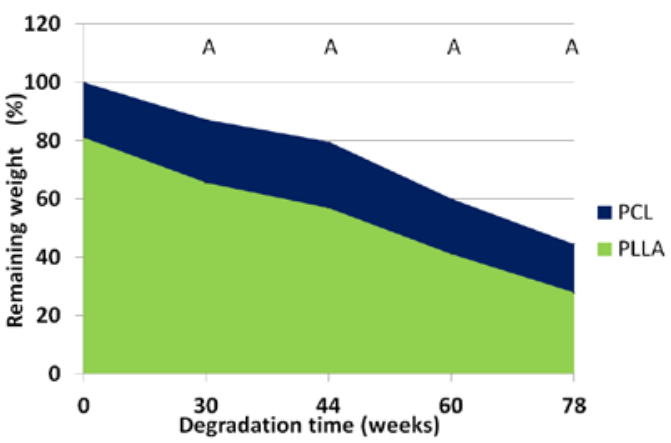

\section{PLLAb-H}

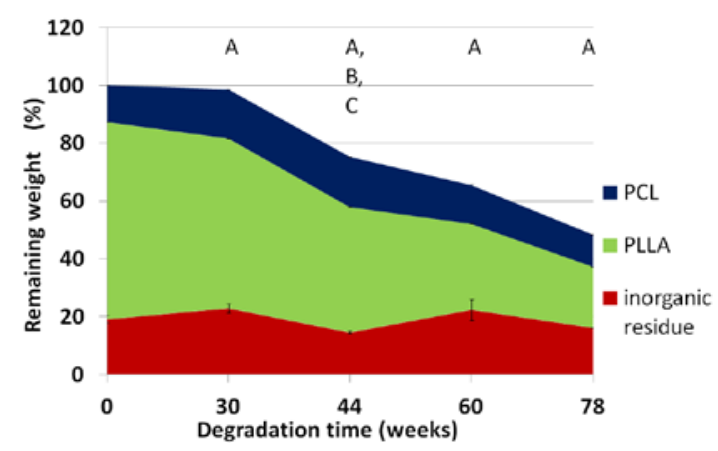

\begin{tabular}{|c|c|c|c|c|c|c|c|}
\hline & Weeks & $M_{w}(\mathrm{Da})$ & $\mathrm{M}_{\mathrm{w}} / \mathrm{M}_{\mathrm{w} 0}$ & PDI & WPCL/WPCL & WPLLA/WPLLA & $\mathrm{k}\left(\right.$ day $\left.^{-1}\right)$ \\
\hline \multirow[t]{2}{*}{ PCLb } & 0 & $1.74 \times 10^{5}$ & 1.00 & 1.51 & $100 \%$ & $100 \%$ & \multirow{2}{*}{$1.71 \times 10^{-3}$} \\
\hline & 78 & $6.46 \times 10^{4}$ & 0.37 & 1.55 & $72 \%$ & $43 \%$ & \\
\hline \multirow[t]{2}{*}{ PLLAb } & 0 & $1.72 \times 10^{5}$ & 1.00 & 1.62 & $100 \%$ & $100 \%$ & \multirow{2}{*}{$2.42 \times 10^{-3}$} \\
\hline & 78 & $5.30 \times 10^{4}$ & 0.31 & 3.47 & $80 \%$ & $31 \%$ & \\
\hline \multirow[t]{2}{*}{ PCLb-H } & 0 & $2.07 \times 10^{5}$ & 1.00 & 1.62 & $100 \%$ & $100 \%$ & \multirow{2}{*}{$1.14 \times 10^{-3}$} \\
\hline & 78 & $9.79 \times 10^{4}$ & 0.47 & 1.45 & $96 \%$ & $35 \%$ & \\
\hline \multirow[t]{2}{*}{ PLLAb-H } & 0 & $2.40 \times 10^{5}$ & 1.00 & 1.60 & $100 \%$ & $100 \%$ & \multirow{2}{*}{$2.80 \times 10^{-3}$} \\
\hline & 78 & $5.00 \times 10^{4}$ & 0.21 & 3.90 & $87 \%$ & $31 \%$ & \\
\hline
\end{tabular}

Table 1. Evolution of molecular weight, relative weight loss of each phase and hydrolysis coefficient

Figure 3 shows the evolution of sample porosity up to Week 60, after which sample crumbling made it impossible to weigh the samples before drying and to evaluate porosity by gravimetric means. Porosity increased as a result of degradation for all scaffolds by around $2-3 \%$. There 
was no significant difference in porosity for PCLb-H, as compared with porosity at initial time, and only for time equal to 34 weeks for PLLAb-H.

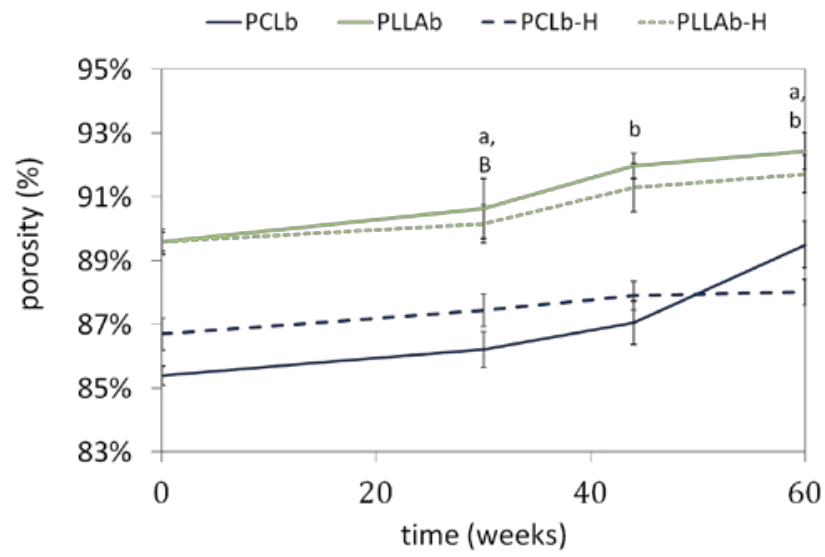

Figure 3. Evolution of sample porosity with degradation time. Error bars represent standard deviation ( $N=7$ when integrity made it possible). Significance $(p<0.05)$ compared to same scaffold at day 0 is signalled as: $(a) P C L b,(b)$ $P L L A b,(A) P C L b-H$ and (B) PLLAb-H.

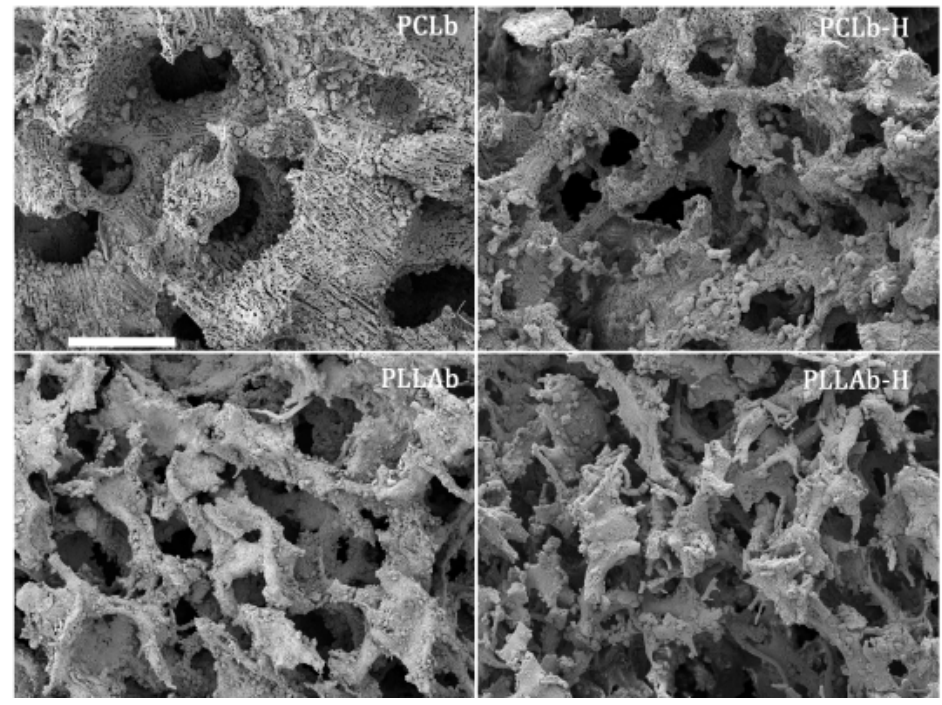

Figure 4. Microstructure of polyester scaffolds after 78 weeks of degradation (bar size: $300 \mu \mathrm{m}$ )

After 78 weeks of degradation the overall gross morphology of the scaffolds showed no visible differences with the non degraded samples, and the microstructure was generally conserved (Figs 1 and 4). However, in the PLLA rich blends (PLLAb and PLLAb-H), broken struts and some loss of integrity can be seen, which was due to the fragile nature of PLLA (Tg above ambient temperature). The size of the PLLA inclusions in PCLb decreased as a result of degradation, while the size of the inclusions stayed nearly the same in the PCLb-H samples. At a finer level (see Fig. S1), degradation appeared as voids created in the matrix (PCLb) or as a progressive contraction of the microstructure (PCLb-H, PLLAb), likely due to the reorganization and recrystallization of the matrix polymer.

\section{Evolution of crystallinity and crystalline morphology}



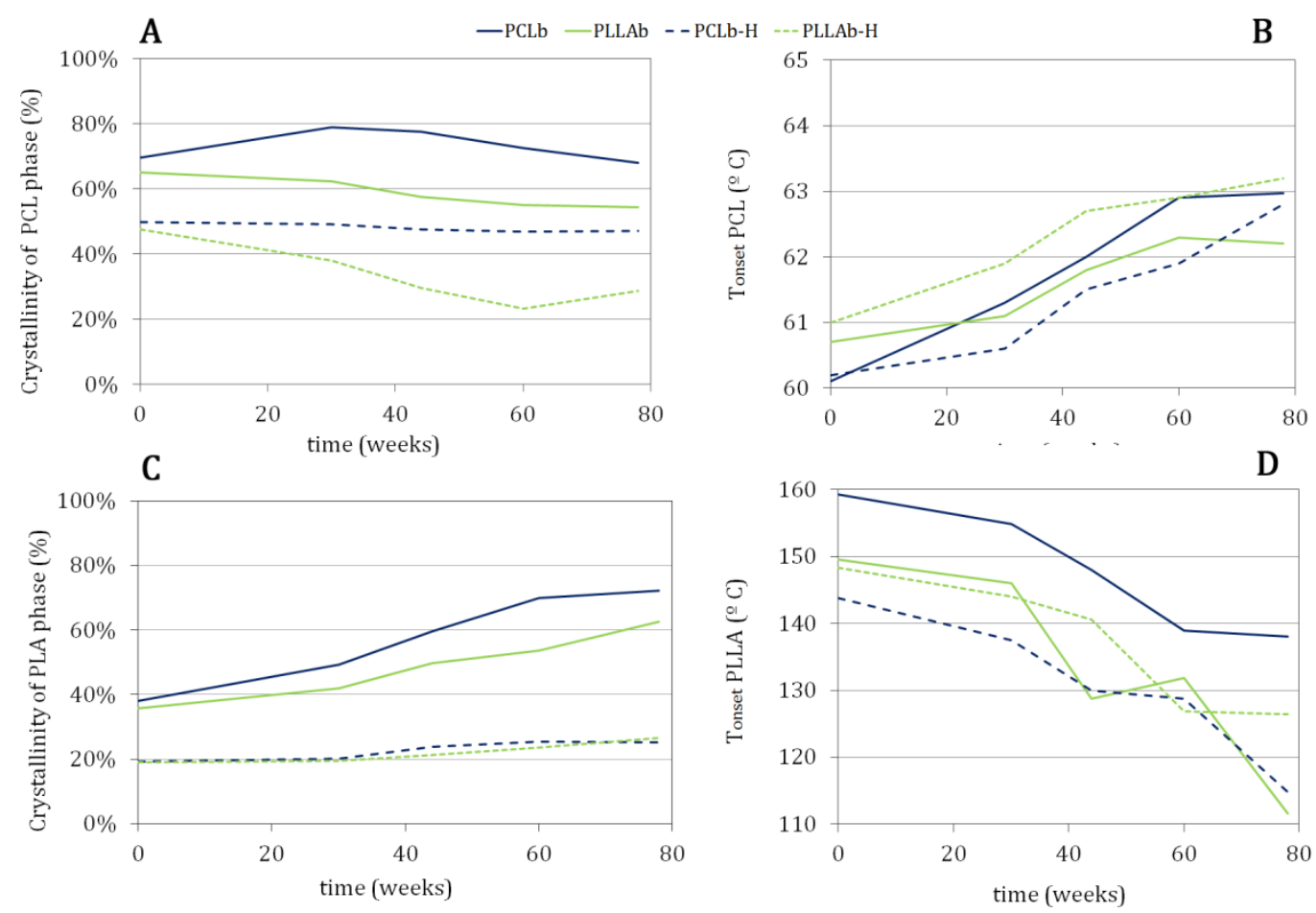

Figure 5. DSC-based values of crystallinity and fusion onset temperature of PCL $(A, B)$ and PLLA $(C, D)$ phase in the different blends

The evolution of crystallinity in the PCL phase (Figure 5A) and PLLA phase (Figure 5C) measured during the first heating scan is shown for the different blends. Initially, the crystallinity of both phases was always lower in the composite samples (shown in dotted lines) than in their pure blend counterpart. The crystallinity of the PCL phase was around $70 \%$ for PCLb and PLLAb, while it was around $50 \%$ for the composites. The same was found for the crystallinity of the PLLA phase, which was around $40 \%$ for the blended samples and $20 \%$ for the composites. Although there was no significant difference or decrease in the PCL phase crystallinity in any of the blends throughout the degradation period, there was an increase in PLLA phase crystallinity: a moderate increase in the PCLb-H and PLLAb-H blends (from around 19 to around $26 \%$ crystallinity) and a dramatic increase in the PCLb and PLLAb samples (from around $40 \%$ to more than $60 \%$ ). At the same time, the melting temperature of the $P C L$ phase tended to rise slightly (Figure 5B), while in PLLA it tended to decrease (Figure 5D). The onset temperature increased by $2-3{ }^{\circ} \mathrm{C}$ for the $\mathrm{PCL}$ phase and decreased by more than $20{ }^{\circ} \mathrm{C}$ for the PLLA phase $(40$ ${ }^{\circ} \mathrm{C}$ in the case of the PCLb sample) 


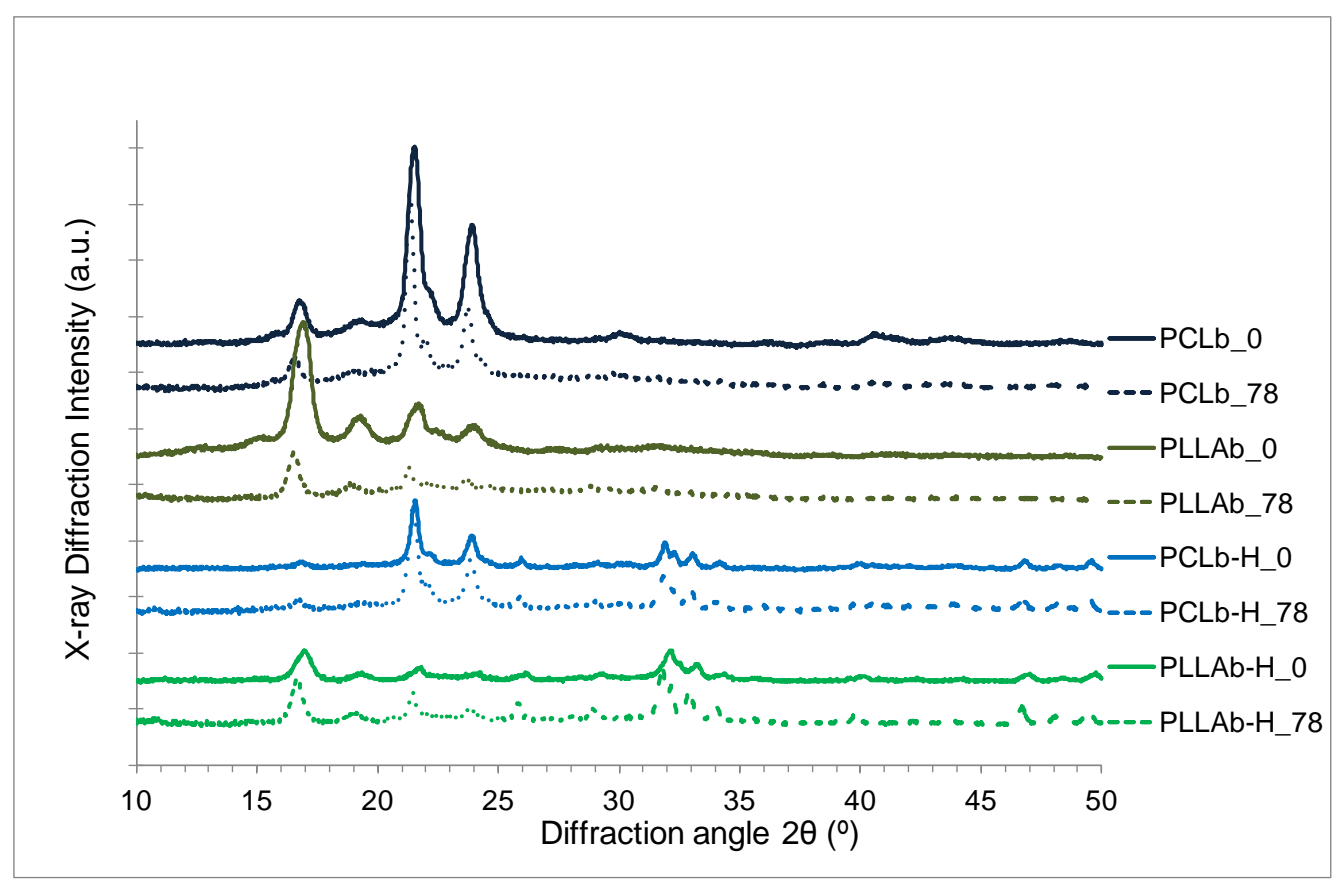

Figure 6. XRD patterns of non-degraded (plain line) and degraded (dotted line) samples at 78 weeks

The evolution of the crystalline phase in the polymer was studied using XRD measurements. The results obtained for non-degraded and 78-week degraded samples are shown in Fig 6. Typical peaks corresponding to the PLLA phase appear at $2 \theta=16.6^{\circ}$ ([110/200] planes), $2 \theta=$ $18.9^{\circ}$ ([203] plane) and $2 \theta=25.8^{\circ}$ ([222] plane) [47]. Peaks for PCL appear at $2 \theta=21.6^{\circ}$ and $2 \theta=23.8^{\circ}$ resulting from diffraction on the [110] and [200] planes, respectively (PCL has a crystalline structure with polyethylene-like orthorhombic cell disposition, with lattice parameters $a=0.748 \mathrm{~nm}, b=0.498 \mathrm{~nm}$ and $c=1.727 \mathrm{~nm}$ ) [48], whereas the hydroxyapatite peaks appear, among others at $26^{0} ; 31.8^{0} ; 32.2^{0} ; 32.9^{0} ; 40^{\circ} ; 49^{\circ}$ (respectively, accounting for reflection on the planes of Miller indices [002], [211], [112] and [300], [130], [213]), which corresponds to a hexagonal structure, with lattice parameters $a=0.943 \mathrm{~nm}, \mathrm{~b}=0.943 \mathrm{~nm}$ and $c=0.688 \mathrm{~nm}$ ) [49]. Changes in the peak Intensity and half-width were observed as a consequence of the degradation process. The relative variation of PCL and PLLA intensity peaks can be seen to depend on the sample composition. PCL rich samples (PCLb and PCLb-H) showed an increase in peak intensity and a decrease in half-width, indicating an increase in crystallinity and crystal size. As PLLA rich samples lose more mass than PCL rich samples, the changes in peak intensity are bigger in PLLAb and PLLAb-H than in PCL rich samples. The changes are less appreciable in samples containing hydroxyapatite, as it affects the degradation process.

Half-width measured from DRX patterns is related to crystal size according to Eq 1. Fig 7 shows the change in crystal size with degradation time. For the sake of clarity, only the data of one peak of each phase is shown as the other peaks followed a similar trend. It can be seen that PCL crystal size increases as degradation proceeds, while PLLA crystal size does not show any clear trend. In the case of the composite samples (PCLb-H and PLLAb-H), the scatter of the results made it impossible to draw any clear conclusions. 


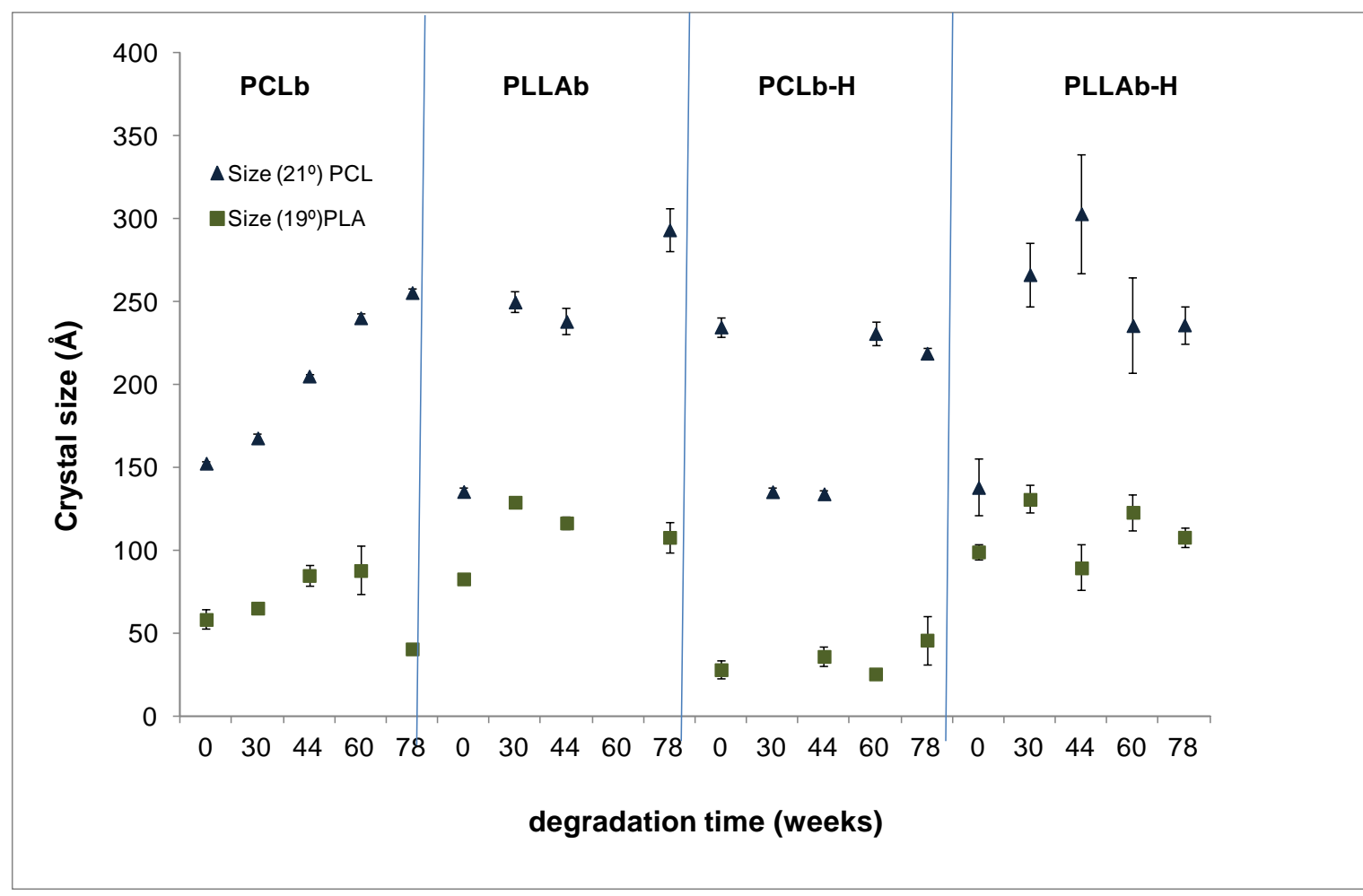

Figure 7. Crystal size evolution with degradation time

\section{Mechanical properties}

The evolution of the mechanical properties is shown in Fig 8 . The scaffolds, when compressed,
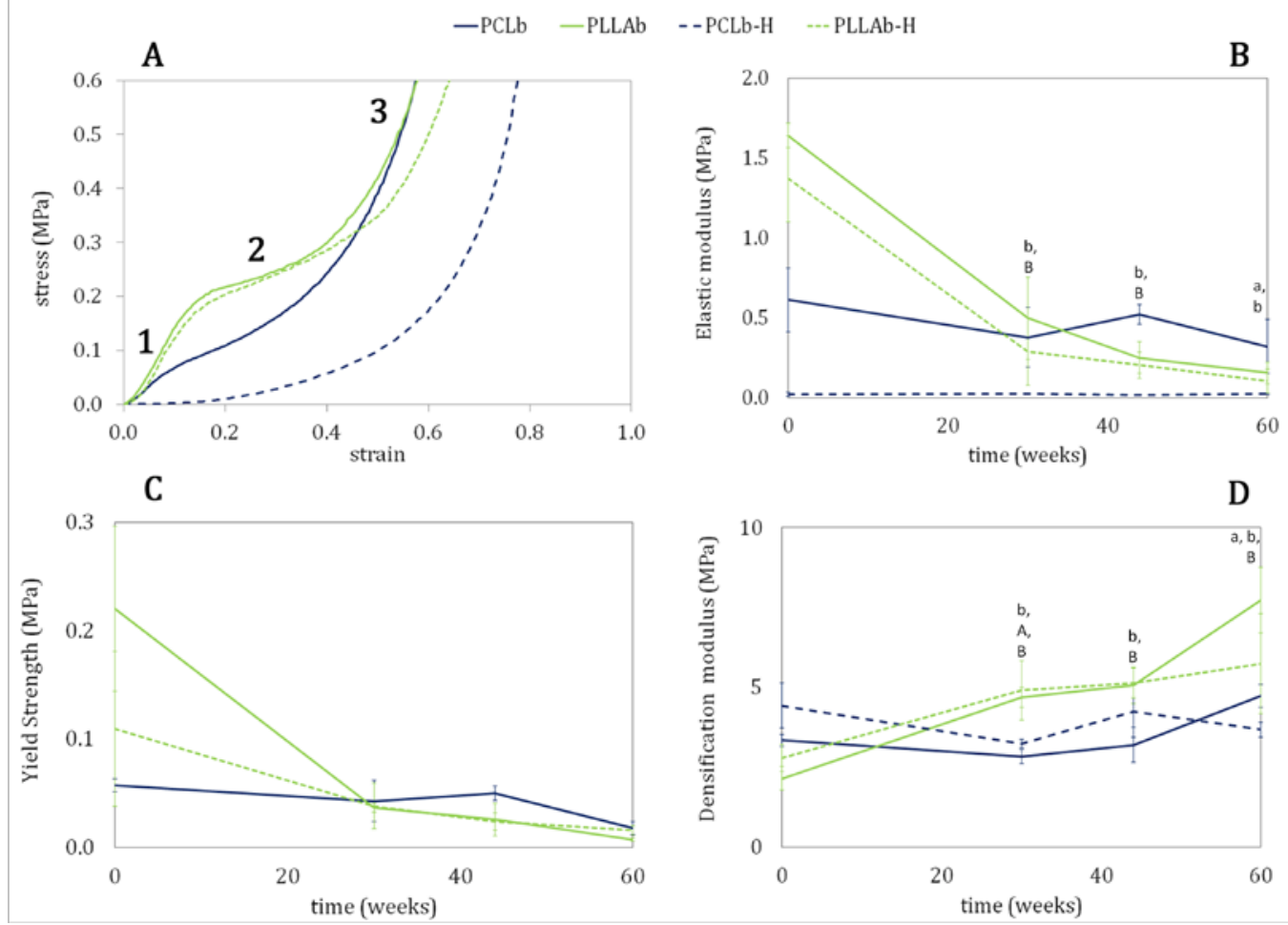

Figure 8. Mechanical compressive properties of the scaffolds. Typical stress strain curve for scaffolds with

1i its three zones at time zero (A) evolution of the elastic modulus with time (B) evolution of the yield strength with time (C) and evolution of the densification modulus with time. ( $N=7$ when integrity made it possible). Significance ( $p<0.05$ ) compared to same scaffold at day 0 is signalled as: (a) PCLb, (b) PLLAb, (A) PCLb-H and (B) PLLAb-H. 
show a stress strain curve with three stages, as is usual in porous samples. The first stage is linear and corresponds to the elastic response of the porous structure. The second stage corresponds to the progressive collapse of the porous structure at nearly constant stress and is known as the plateau zone. The final stage consists of a progressive densification of the structure due to the total collapse of the pores, leading to a steeper slope in the stress-strain curve. The elastic modulus is defined as the slope of the first linear zone (Fig 8B). The yield strength is the tension at which the plateau zone starts (Fig $8 \mathrm{C}$ ). The densification modulus is the tangent of the maximum modulus reached during densification (Fig 8D). The elastic modulus and yield strength of as-synthesized scaffolds were higher for PLLAb and PLLAb-H, as can be seen in Figure $8 \mathrm{~B}$ y C; PLLA is in a glassy state at room temperature, while PCL is rubbery, which explains the difference observed. Including the inorganic phase does not lead to a mechanical strengthening in the case of these materials: PCLb-H has the lowest modulus and the yield strength was undetectable for these samples. Nevertheless, after 30 weeks of degradation, PLLA rich scaffolds lost more than half of their strength and rigidity and there was no significant difference between PLLAb and PLLAb-H on one hand and PCLb on the other. However, the densification modulus of the PLLA-based blends increased with degradation time, while PCL-based blends had a relatively constant densification modulus.

\section{Evolution of molecular weight}
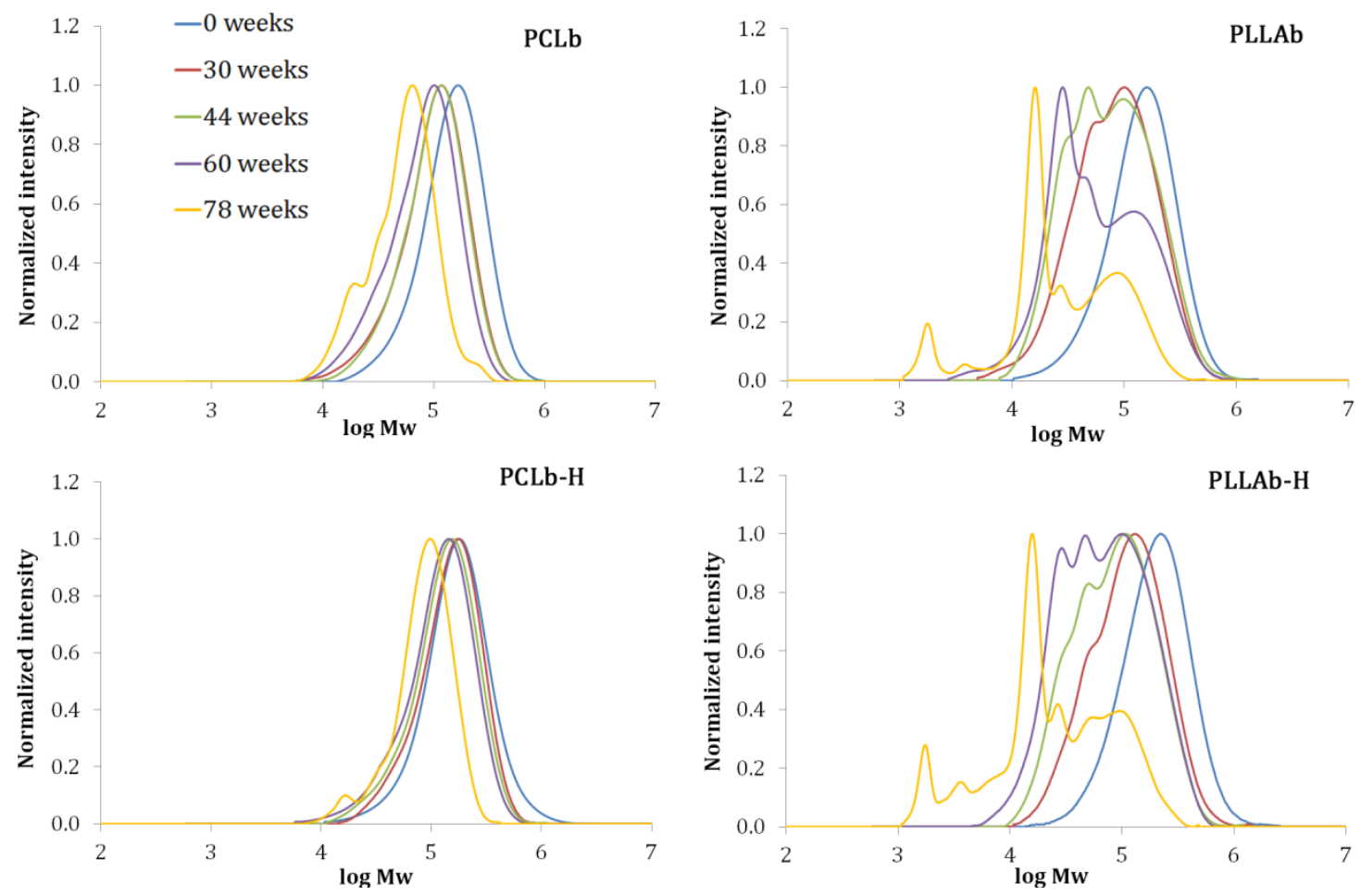

Figure 9. Evolution of molecular weight distribution with degradation time

The evolution of the molecular weight distribution as determined by GPC is depicted in Fig 9 and data for the mean molecular weights and polydispersity index can be found in Table 1 . The evolution pattern was different for PLLA rich and PCL rich blends; whereas the distribution 
of PCL rich blends showed little shifting towards lower molecular weights (from 1.74.10 6.46.10 ${ }^{4}$ Da for PCLb and from $2.07 \cdot 10^{5}$ to $9.79 \cdot 10^{4}$ Da for PCLb-H) while undergoing a slight broadening, which was reflected in a modest increase in the polydispersity index (from 1.51 to 1,55 for PCLb and from 1.62 to 1.45 for PCLb-H) (see Table 1). The PLLA rich blend distribution changed dramatically after only 44 weeks of degradation as can be seen in Figure 9. Subpopulations with different molecular weights appear gradually and with longer degradation time the distribution consists of a sum of nearly monodisperse peaks of very different molecular weights (from $10^{3}$ up to $10^{5}$ ), which correlated with a dramatic increase in the polydispersity index (from 1.62 to 3.47 for PLLAb and from 1.60 to 3.90 for PLLAb-H).

The presence of HAp had different effects on the PLLA and PCL phases. Whereas molecular weight decreased more dramatically for the PLLAb-H than for the PLLAb sample; for PCL rich blends the PCLb-H molecular weight decreased less than its PCLb counterpart. The hydrolysis coefficient $k$ was determined from the slope of the linear part of a semi-logarithmic plot of $\mathrm{Mn} / \mathrm{Mn}_{0}$ as described by Tsuji [45] (see plot and trends in Figure S2). In the case of PCL blends $\mathrm{R}^{2}>0.9$ was obtained using the whole degradation period; in the PLLA blend at the last time point there was an increase in the slope, probably due to an acceleration of the degradation process and a deviation from the equilibrium assumption on which the calculus is based. In this case $k$ was calculated from all time points except the last, and coefficients $R^{2}>0.95$ were found. The results are presented in Table 1. The PCL-based samples had lower hydrolysis coefficients than PLLA-based samples, as expected from the higher density of ester bonds in the latter. Interestingly, while the inclusion of HAp leads to a lower hydrolysis coefficient in the PCL rich sample, it leads to an increase in $k$ for the PLLA-based sample, which was consistent with the other results obtained.

\section{Discussion}

\section{Material Properties Prior to Degradation}

Highly porous scaffold bases were produced on PCL/PLLA/HAp, in whichPCL and PLLA were phase separated. As a result of the preparation process a double pore structure was obtained. The scaffolds thus obtained possess an interconnected porous network apt for cell and tissue colonization, together with interconnected microporosity to enhance fluid permeability and degradability. They should be suitable materials for use as a template for non-load-sharing tissue engineering applications [50]. An incomplete pore interconnection could constrain the overall biological system and limit blood vessel invasion, which is essential for tissue ingrowth into the porous scaffolds [51, 52]. In this aspect, these scaffolds show improved porosity over those presented in previous works [53] prepared without porogen and which only possessed microporosity. As a result, the materials described in this paper have higher porosity (around $90 \%$ versus around $80 \%$ for the microporous membranes). They also have a lower modulus (around 1-2 MPa versus 4-11 MPa for microporous membranes). The crystallinity of both the PLLA and PCL phases is in the same order of magnitude as synthesized microporous membranes and the new scaffolds described here (around 40\% for PLLA phase and around $60 \%$ for PCL phase). The high crystallinity of both polymeric phases is related to the crystallization from solution, which occurs in both types of substrates. The modulus of the 
scaffolds is low as compared to the modulus values of bone, but one has to bear in mind that when used in load-bearing sites, such substitutes are often combined with titanium plates to provide mechanical integrity, so that a low modulus is not a relevant drawback for their intended use in bone tissue engineering.

The presence of HAp nanoparticles led to a decrease of PCL and PLLA crystallinity in both sample types, showing that the high quantity of nanoparticles is liable to limit the crystallization rate of both phases during the production process [54]. This does not seem to affect the crystal size of PCL, as can be seen from the values of the fusion onset of PCL at $t_{0}$. In neither PCLb-H nor PLLAb-H did the samples show any significant difference with the onset of the pristine polymer samples. On the other hand, PLLA crystal size is dramatically reduced in the presence of HAp in the case of PCLb, but not in that of PLLAb, which indicates that nanoparticle distribution may be quite different in PCL rich and PLLA rich samples.

This reduced crystallinity could explain why the mechanical properties do not improve but rather worsen when the scaffolds are reinforced with HAp, a phenomenon which we had also observed in previous studies $[55,28]$. Moreover, due to the high crystallinity of the samples, HAp may act as a drawback rather than as a physical crosslink, as it would in a totally amorphous polymer. It has also been pointed out in the literature that the interfacial bonding strength of apatite with PLLA is poor [56]. Functionalizing HAp particles with PLLA oligomers was the key to obtaining better properties in the work by Hong et al. [57], showing the overwhelming effect of interfacial bonding strength between polymer and ceramic particles in mechanical reinforcement by nanoparticles.

\section{Degradation behavior. Influence of macroporosity}

In this work we examined the degradation behavior of macroporous scaffolds. Comparing the values obtained with microporous membranes in our previous study [53] at similar timepoints (65 versus 60 weeks) we see that the decrease in molecular weight is very similar (0.32 of initial Mw for PLLAb and 0.67 of initial Mw for PCLb), showing that the degradation behavior at the molecular level was not influenced by the presence of macropores. Nevertheless, the weight loss at this same timepoint was much higher for macroporous samples (remaining weight $60.1 \%$ for PLLAb, whereas microporous samples had around $82 \%$, and $83 \%$ for PCLb, and microporous samples had a remaining weight of $92 \%$ ). This may be due to the greater release of soluble degradation products from the interconnected structure, but more likely it indicates that erosion may be an important factor through which macroporous samples lose weight. Erosion will probably be increased here as a result of shaking and of the increased water flow throughout the interconnected pore structure.

\section{Influence of blending on weight loss and molecular weight}

The degradation of PCL-PLA blends has been extensively studied and it has generally been shown that PLLA is less degraded in PCL rich blends than in PLLA rich blends [45]. This is generally explained in terms of impaired water diffusion through the $\mathrm{PCL}$ matrix limiting the hydrolysis rate of PLLA inclusions. This was also the case in our present work, where weight loss associated to the PLLA phase was higher in the PLLAb blend than in the PCLb blend. Although Tsuji observed that degradation of the PCL phase was unaffected by the presence of PLLA, in our work PCL weight loss was higher in PCLb than in PLLAb blends, which cannot be 
explained through the diffusion factor, as in the former case. It is also in disagreement with the findings of Fukushima et al. [58], who found that PCL degraded more rapidly in PDLA rich blends. Here it is worth mentioning that the films used by Fukushima had far higher diffusion lengths $(100 \mu \mathrm{m})$ than our scaffold $(1-10 \mu \mathrm{m})$ and so an interaction of short degraded polylactic acid chains with the PCL inclusions is much less probable.

An explanation for the reduced weight loss may be the lower crystallinity of PCL in PLLA rich samples; PCL degrades in the amorphous phase, due to its higher hydrolysis rate [59], as shown by the slight increase in $T_{m}\left(2-3^{\circ} \mathrm{C}\right)$, which is due to reorganization and crystallite growth as a result of chain scission in the intercrystalline zone [45]. Tsuji showed that the hydrolysis rate in the amorphous zone of PLLA was higher at higher crystallinities, due to the impaired chain packing of the intercrystalline chains tied in adjacent spherulites. Thus, a more amorphous PCL may paradoxically hydrolyze less than a crystalline one. This is consistent with the results obtained for $\mathrm{k}$ values of PCLb and PCLb- $\mathrm{H}$, where the more amorphous PCLb-H shows a lower hydrolysis coefficient than the more crystalline PCLb.

\section{Influence of HAp reinforcement on weight loss and molecular weight}

As regards PLLA degradation, our results show that by adding HAp nanoparticles after an induction period of around 30 weeks, degradation significantly increased in the PLLA phase. This is in contrast with the results obtained by Verheyen et al. [60], in which Hydroxyapatite and calcium phosphate reduced the PLLA degradation rate. However, most studies on PLLA composites show that degradation increases when mixed with HAp [61], and it is also known that composite devices are resorbed faster in vivo [62]. Our observation of a higher hydrolysis rate in PLLAb than PLLAb-H samples during the first 30 weeks of degradation would be consistent with Verheyen et al's results, whereas after 78 weeks of degradation the relative weight loss in these samples was similar.

On the other hand, in PCL rich blends, PLLA remaining weight was lower (Table 1) when HAp was present ( $35 \%$ instead of $43 \%$ ). This may be due to differences in HAp distribution between both phases, and its influence on crystal morphology, as PLLA crystal size inferred from Tm and XRD (see Fig. 5D and Fig. 7) was very similar in PLLAb and PLLAb-H blends (onset melting temperatures were $149{ }^{\circ} \mathrm{C}$ and $148{ }^{\circ} \mathrm{C}$ respectively), whereas in $\mathrm{PCL}$ rich blends there was a big difference in PLLA crystal size, with very tiny PLLA crystal size in the presence of Hap (onset melting temperatures were $159{ }^{\circ} \mathrm{C}$ for PCLb and $144{ }^{\circ} \mathrm{C}$ for PCLb-H).

As far as we know there is not much data available in the literature on the influence of HAp on $\mathrm{PCL}$ degradation, especially on long term degradation behavior. Ural et al. [63] observed a lower molecular weight loss in their PDLA-PCL amorphous composites that was proportional to the amount of HAp. However, this study only lasted 6 weeks and most of the degradation may have been due to the hydrolysis of PDLA segments. Ang et al. [64] found increased degradation of PCL-HAp composites with increasing mass loss at higher HAp contents in an accelerated degradation using $\mathrm{NaOH} 5 \mathrm{M}$, although the mechanism of this degradation assay may hardly be relevant to explain our results. In most studies very short times are used (from 7 days to 6 weeks) and the weight losses observed are mainly due to inorganic phase dissolution (when using TCP, see for example Lu et al. [65] or HAp in thin PCL layer Kim el al. [66]) as physical degradation of $\mathrm{PCL}$ is known to occur on a much larger timescale. As we have already 
mentioned, not much information has been published on long term degradation of PCL-HAp composites accompanied by precise data such as GPC and DSC measurements. Our results tend to show that $\mathrm{PCL}$, when reinforced with $\mathrm{HAp}$, is more resistant to hydrolysis, as shown by the lower hydrolysis coefficient observed for PCLb-H samples and the reduced weight loss of these samples. This cannot be explained by the lower crystallinity obtained in samples that contain HAp. Nevertheless, it may be that introducing HAp in composite samples triggers subtle phase changes in the composites and thus the influence of the HAp and PLLA segments on PCL degradation behavior cannot be definitively isolated from each other. A long term study of PCL degradation when reinforced with HAp in samples with varying degrees of crystallinity using qualitative methods such as GPC and DSC is needed to ultimately determine the respective influence of both these factors on $\mathrm{PCL}$ hydrolytic degradation.

\section{Degradation mechanism and evolution of crystallinity}

According to Tsuji [45], degradation of the crystalline phase leads to crystallite thinning and lower $T_{m}$, while in the amorphous phase degradation leads to recrystallization in the domains near the spherulites, thus producing coarser crystallites that melt at higher temperatures. Here PLLA showed falling Tm, although XRD showed no clear trend in crystallite size. We are inclined to think that rather than being due to crystallite thinning, together with the rise in crystallinity observed in the PLLA phase, this may be explained by the preferential degradation of the amorphous regions and the new crystals produced by the reorganization of the degraded PLLA chains. These shorter chains would reorganize in small crystals, producing a dispersion of crystal size in the degraded samples, as measured by XRD. Recrystallization may be a mechanism that protects PLLA from further hydrolysis; for this reason, PLLA in samples that contain HAp may have higher levels of degradation as its recrystallization is impeded by the presence of nanoparticles.

In the case of $\mathrm{PCL}$, the small changes in crystallinity are thought to be due to the preferential degradation of the amorphous phase. The increase in the PCL crystal size, observed in XRD, could be related to recrystallization during degradation. This is likely to happen at $37{ }^{\circ} \mathrm{C}$ in water-plasticized PCL chains and correlates with the slight increase of 2-3 ${ }^{\circ} \mathrm{C}$ in the onset melting temperature observed by DSC.

\section{Mechanical properties}

As expected, the mechanical properties of the scaffolds declined with degradation time. Although glassy PLLA is initially much more rigid than PCL (which is rubbery at ambient temperature), soon after 30 weeks there is no significant difference between the yield strength or elastic modulus of PLLA rich and PCL rich samples. The densification modulus of the PLLA-based blends increased with degradation time, whereas the PCL-based blends had a relatively constant densification modulus. This may be related to the increasing crystallinity, observed by DSC in the PLLA phase, while the PCL phase showed nearly constant crystallinity.

These materials are designed to be used in tissue engineering and the contribution of the regenerated tissue is thought to make up for the mechanical properties of the implant when material properties are lost due to degradation. However, these implants are not meant to be load-bearing and if implanted in load-bearing sites should always be used in combination with titanium plates as load-bearing elements. These materials have been used in an in vivo study 
using a critical size defect in the radius in rabbits, showing good regeneration and torsional properties after 16 weeks that were similar to those obtained with reference material (Copios $\left.{ }^{\circledR}\right)$ and significantly higher than void defects (Rodenas et al. to be published).

\section{Conclusions}

Poly(L-lactic acid)(PLLA)/poly(e-caprolactone)(PCL) highly porous scaffolds were developed by a dual technique of freeze extraction combined with porogen leaching to obtain a double pore structure with and without hydroxyapatite(HAp) (size $<100 \mathrm{~nm}$ ). High porosities $(>85 \%)$ were acquired, and most importantly the pores were interconnected, which is of crucial importance in tissue engineering in order to allow cell colonization and fluid flow inside the structure.

A study was carried out on long-term (78 weeks) hydrolytic degradation and the effects of hydroxyapatite filler. The results show that the introduction of HAp leads to a dramatic increase in PCL remaining weight (more pronounced when PCL was the main phase; $72 \%$ for PCLb and 96\% for PCLb-H). On the other hand, the PLLA's remaining weight decreased in PCL rich blends, from $43 \%$ in PCLb to 35\% in PCLb-H and had no effect on PLLA rich blends.

The evolution pattern of molecular weight distribution was different for PLLA and PCL rich blends. Molecular weight decreased most dramatically in the PLLAb-H sample, followed by the PLLAb sample, PCLb, and the PCLb-H sample that showed the lowest molecular weight loss. Whereas the molecular weight distribution of PCL rich blends showed a broadening reflected in an increase in the polydispersity index of $2 \%$ for PCLb, the PLLA rich blend distribution changed dramatically with an increasing in the polidispersity index of $144 \%$ for PLLAb-H.

The crystallinity of the PCL and PLLA phases were always lower in the composite samples than in their pure blend counterparts, and the evolution of the crystallinity of both phases during degradation followed different trends. While there was a dramatic increase in the PLLA phase crystallinity for PCLb and PLLAb samples (from around 40\% to more than 60\%), there was a moderate increase in the PLLA phase crystallinity for the PCLb-H and PLLAb-H blends (from around 19 to around $26 \%$ ).

As expected, the mechanical properties of the scaffolds degenerated with degradation time. Although glassy PLLA is initially much more rigid than PCL (which is rubbery at ambient temperatures), soon after 30 weeks there was no significant difference between the yield strength or elastic modulus of PLLA rich or PCL rich samples. The densification modulus of the PLLA-based blends increased with degradation time, while PCL-based blends had a relatively constant densification modulus.

Future studies will include an in vivo study of these composite scaffolds to fully elucidate their efficacy for use in biomedical applications. The scaffolds have already been implanted in bones in animal models (the results to be published shortly), showing good regeneration and torsional properties after 16 weeks. 


\section{Acknowledgements}

The authors are grateful for the support of the Biomedical Research Networking Center in Bioengineering, Biomaterials, and Nanomedicine, an initiative funded by the VI National R\&D\&i Plan 2008-2011, Iniciativa Ingenio 2010, and Consolider Program.

\section{References}

[1] Wang S, Kempen DH, Simha NX, Lewis JL, Windebank AJ, Yaszemski MJ, Lu L. Photo-cross-linked hybrid polymer networks consisting of poly(propylene fumarate) and poly(caprolactone fumarate): Controlled physical properties and regulated bone and nerve cell responses. Biomacromolecules. 2008;9:1229-1241

[2] Mano JF, Sousa RA, Boesel LF, Neves NM, Reis RL. Bioinert, biodegradable and injectable polymeric matrix composites for hard tissue replacement: state of the art and recent developments. Compos Sci Technol 2004;64:789-817

[3] Drotleff S, Lungwitz U, Breunig M, Dennis A, Blunk T, Tessmar J. Biomimetic polymers in pharmaceutical and biomedical sciences. Eur J Pharm Biopharm 2004;58:385-407

[4] Suchanek W, Yoshimura M. Processing and properties of hydroxyapatite- based biomaterials for use as hard tissue replacement implants. J Mater Res 1998;13:94-117

[5] Ma PX. Biomimetic materials for tissue engineering. Adv Drug Deliv Rev. 2008;60:184-198

[6] Ma P, Langer R. Degradation, structure and properties of fibrous nonwoven poly(glycolic acid) scaffolds for tissue engineering. Polymers in Medicine and Pharmacy. 1995;394:99-104

[7] Zhang R, Ma P. Poly(alpha-hydroxyl acids) hydroxyapatite porous composites for bone-tissue engineering. I. Preparation and morphology. J Biomed Mater Res. 1999;44:446-455

[8] Zhang R, Ma P. Degradation behavior of porous poly(alpha-hydroxy acids)/hydroxyapatite composite scaffolds. Abstracts of Papers of the American Chemical Society. 2000;220:U251-U251

[9] Chen $\mathrm{V}, \mathrm{Ma} \mathrm{P}$. The effect of surface area on the degradation rate of nano-fibrous poly(L-lactic acid) foams. Biomaterials. 2006;27:3708-3715

[10] Engelberg I, Kohn J. Physicomechanical Properties of Degradable Polymers used in Medical Applications - a Comparative-Study. Biomaterials. 1991;12:292-304

[11] Li S. Hydrolytic degradation characteristics of aliphatic polyesters derived from lactic and glycolic acids. J Biomed Mater Res. 1999;48:342-353

[12] Amass W, Amass A, Tighe B. A review of biodegradable polymers: Uses, current developments in the synthesis and characterization of biodegradable polyesters, blends of biodegradable polymers and recent advances in biodegradation studies. Polym Int. 1998;47:89-144

[13] Vert M, Mauduit J, Li S. Biodegradation of Pla/ga Polymers - Increasing Complexity. Biomaterials. 1994;15:1209-1213

[14] Schmitt E, Flanagan D, Linhardt R. Importance of Distinct Water Environments in the Hydrolysis of Poly(dl-Lactide-Co-Glycolide). Macromolecules. 1994;27:743-748

[15] Pitt, C. G., in Biodegradable Polymers and Drug Delivery Systems, ed. R. L. Chasin Ma. Marcel Dekker, New York, 1990, pp. 71 \pm 120.

[16] Cha Y, Pitt CG. The Biodegradability of Polyester Blends. Biomaterials. 1990;11:108-112

[17] Gilding D, Reed A. Biodegradable Polymers for use in Surgery - Polyglycolic-Poly(actic Acid) Homopolymers and Copolymers.1. Polymer. 1979;20:1459-1464

[18] Kalb B, Pennings A. General Crystallization Behavior of Poly(I-Lactic Acid). Polymer. 1980;21:607612 
[19] Pitt C, Gratzl M, Kimmel G, Surles J, Schindler A. Aliphatic Polyesters .2. The Degradation of Poly(dlLactide), Poly(epsilon-Caprolactone), and their Copolymers In vivo. Biomaterials. 1981;2:215-220

[20] Shikinami $Y$, Okuno M. Bioresorbable devices made of forged composites of hydroxyapatite (HA) particles and poly-L-lactide (PLLA): Part I. Basic characteristics. Biomaterials. 1999;20:859-877.

[21] Supová M. Problem of hydroxyapatite dispersion in polymer matrices: a review. J Mater Sci: Mater Med. 2009;20:1201-1213

[22] Webster TJ, Ergun C, Doremus RH, Siegel RW, Bizios R. Enhanced functions of osteoblasts on nanophase ceramics. Biomaterials. 2000;21:1803-1810

[23] Hutmacher D, Kirsch A, Ackermann K, Huerzeler M: Processing and Fabrication of Bioresorbable Implants and Devices - State of the Art and Future Perspectives. In: Processing and Fabrication of Advanced Materials VI, VOLS 1 \& 2. Stark GB, Horch R, Tancos E, editors. 1998:1645-1660.

[24] Liao S, Cui F. In vitro and in vivo degradation of mineralized collagen-based composite scaffold: Nanohydroxyapatite/collagen/poly(L-lactide). Tissue Eng. 2004;10:73-80

[25] Nejati E, Firouzdor V, Eslaminejad MB, Bagheri F. Needle-like nano hydroxyapatite/poly(L-lactide acid) composite scaffold for bone tissue engineering application. Materials Science \& Engineering CBiomimetic and Supramolecular Systems. 2009;29:942-949

[26] Jung Y, Kim S, Kim Y, Kim S, Kim B, Kim S, Choi C, Kim S. A poly(lactic acid)/calcium metaphosphate composite for bone tissue engineering. Biomaterials. 2005;26:6314-6322.

[27] Hutmacher D. Scaffolds in tissue engineering bone and cartilage. Biomaterials. 2000;21:2529-2543

[28] Lebourg M, Suay Anton J, Gomez Ribelles JL. Hybrid structure in PCL-HAp scaffold resulting from biomimetic apatite growth. J Mater Sci: Mater Med 2010;21:33-44.

[29] Causa F, Netti P, Ambrosio L, Ciapetti G, Baldini N, Pagani S, Martini D, Giunti A. Poly-epsiloncaprolactone/hydroxyapatite composites for bone regeneration: in vitro characterization and human osteoblast response. J Biomed Mater Res Part A. 2006;76A:151-162.

[30] Hwang S, Todo M. Characterization of compressive deformation behavior of multi-layer porous composite materials for articular tissue engineering. Science Journal of Mechanical and Technology. 2012;26:1999-2004

[31] Guarino V, Ambrosio L. The synergic effect of polylactide fiber and calcium phosphate particle reinforcement in poly epsilon-caprolactone-based composite scaffolds. Acta Biomaterialia. 2008;4:1778-1787

[32] Charles LF, Shaw MT, Olson JR, Wei M. Fabrication and mechanical properties of PLLA/PCL/HA composites via a biomimetic, dip coating, and hot compression procedure. J Mater Sci: Mater Med. 2010;21:1845-1854.

[33] Lam CXF, Hutmacher DW, Schantz J, Woodruff MA, Teoh SH. Evaluation of polycaprolactone scaffold degradation for 6 months in vitro and in vivo. J Biomed Mater Res A. 2009;90A:906-919

[34] Roohani-Esfahani S, Nouri-Khorasani S, Lu Z, Appleyard R, Zreiqat H. The influence hydroxyapatite nanoparticle shape and size on the properties of biphasic calcium phosphate scaffolds coated with hydroxyapatite-PCL composites. Biomaterials. 2010;31:5498-5509

[35] Rezwan K, Chen Q, Blaker J, Boccaccini A. Biodegradable and bioactive porous polymer/inorganic composite scaffolds for bone tissue engineering. Biomaterials. 2006;27:3413-3431.

[36] Rodenas-Rochina J, Gomez Ribelles JL, Lebourg M. Comparative study of PCL-HAp and PCLbioglass composite scaffolds for bone tissue engineering. J Mater Sci: Mater Med. 2013;24:12931308

[37] Lebourg M, Suay Anton J, Gomez Ribelles JL. Porous membranes of PLLA-PCL blend for tissue engineering applications. European Polymer Journal. 2008;44:2207-2218

[38] Iquierdo Escrig R. Ph.D Thesis: Desarrollo y caracterización de estructuras porosas tridimensionales en polimeros biodegradables, Universidad JAUME I DE CASTELLON, 2007 
[39] Castilla-Cortazar I, Mas-Estelles J, Meseguer-Duenas JM, Ivirico JLE, Mari B, Vidaurre A. Hydrolytic and enzymatic degradation of a poly(epsilon-caprolactone) network. Polym Degrad Stab. 2012;97:1241-1248

[40] Pyda M, Bopp RC, Wunderlich B. Heat capacity of poly(lactic acid). Journal of Chemical Thermodynamics. 2004;36:731-742

[41] Yam W, Ismail J, Kammer H, Schmidt H, Kummerlowe C. Polymer blends of poly(epsiloncaprolactone) and poly(vinyl methyl ether) thermal properties and morphology. Polymer. 1999;40:5545-5552

[42] Klug HP. X-ray diffraction procedures. New York: Wiley, 1967

[43] Guinier A. X-ray diffraction. San Francisco: W. H. Freeman; 1963. p. 121

[44] Luo H, Meng X, Cheng C, Dong Z, Zhang S, Li B. Enzymatic degradation of supramolecular materials based on partial inclusion complex formation between alpha-cyclodextrin and poly(epsiloncaprolactone). J Phys Chem B 2010;114:4739-45

[45] Tsuji H, Ikada Y. Blends of aliphatic polyesters. II. Hydrolysis of Solution-Cast Blends from Poly( Llactide) and Poly(1-caprolactone) in Phosphate-Buffered Solution. J Appl Polym Sci. 1998;67: 405415

[46] Mathieu L, Bourban PE, Manson JAE. Processing of homogeneous ceramic/polymer blends for bioresorbable composites. Composites Sci and Tech. 2006;66:1606-1614

[47] Yasuniwa M, Tsubakihara S, Iura K, Ono Y, Dan Y, Takahashi K. Crystallization behavior of poly(Llactic acid). Polymer. 2006;47:7554-7563

[48] Bittiger H, Marchessault RH, Niegisch WD. Crystal structure of of Poly-Eta-caprolactone. Acta Cryst B 1970;B 26:1923-7

[49] Cardoso GBC, Ramos SLF, Rodas ACD, Higa OZ, Zavaglia CAC, Arruda ACF. Scaffolds of poly (epsilon-caprolactone) with whiskers of hydroxyapatite. J Mater Sci. 2010;45:4990-4993

[50] Kothapalli CR, Shaw MT, Wei M. Biodegradable HA-PLA 3-D porous scaffolds: Effect of nano-sized filler content on scaffold properties Acta Biomaterialia 2005;1:653-662

[51] Boyde A, Corsi A, Quarto R, Cancedda R, Bianco P. Osteoconduction in large macroporous hydroxyapatite ceramic implants: Evidence for a complementary integration and disintegration mechanism. Bone. 1999;24:579-589

[52] Barou O, Mekraldi S, Vico L, Boivin G, Alexandre C, Lafage-Proust M. Relationships between trabecular bone remodeling and bone vascularization: A quantitative study. Bone. 2002;30:604-612

[53] Gaona LA, Gomez Ribelles JL, Perilla JE, Lebourg M. Hydrolytic degradation of PLLA/PCL microporous membranes prepared by freeze extraction. Polym Degrad Stab. 2012;97:1621-1632

[54] Wang S, Kempen DHR, Yaszemski MJ, Lu L. The roles of matrix polymer crystallinity and hydroxyapatite nanoparticles in modulating material properties of photo-crosslinked composites and bone marrow stromal cell responses. Biomaterials. 2009;30:3359-3370

[55] Deplaine H, Lebourg M, Ripalda P, Vidaurre A, Sanz-Ramos P, Mora G, Prosper F, Ochoa I, Doblare M, Gomez Ribelles JL, Izal-Azcarate I, Gallego Ferrer G. Biomimetic hydroxyapatite coating on pore walls improves osteointegration of poly(L-lactic acid) scaffolds. J Biomed Mater Res B. 2013;101

[56] Wang T, Chow LC, Frukhtbeyn SA, Ting AH, Dong Q, Yang M, Mitchell JW. Improve the Strength of PLA/HA Composite Through the Use of Surface Initiated Polymerization and Phosphonic Acid Coupling Agent. J Res Natl Inst Stand Technol. 2011;116:785-796

[57] Hong Z, Zhang P, He C, Qiu X, Liu A, Chen L, Chen X, Jing X. Nano-composite of poly(L-lactide) and surface grafted hydroxyapatite: Mechanical properties and biocompatibility. Biomaterials. 2005;26:6296-6304

[58] Fukushima K, Luis Feijoo J, Yang M. Abiotic degradation of poly(DL-lactide), poly(epsiloncaprolactone) and their blends. Polym Degrad Stab. 2012;97:2347-2355 
[59] Bosworth LA, Downes S. Physicochemical characterisation of degrading polycaprolactone scaffolds. Polym Degrad Stab. 2010;95:2269-2276

[60] Verheyen C, Dewijn J, Vanblitterswijk C, Degroot K. Evaluation of Hydroxylapatite Poly(I-Lactide) Composites - Mechanical Behavior. J Biomed Mater Res. 1992;26:1277-1296

[61] Liao G, Jiang S, Xu X, Ke Y. Electrospun aligned PLLA/PCL/HA composite fibrous membranes and their in vitro degradation behaviors. Mater Lett. 2012;82:159-162

[62] Shikinami Y, Matsusue Y, Nakamura T. The complete process of bioresorption and bone replacement using devices made of forged composites of raw hydroxyapatite particles/poly L-lactide (F-u-HA/PLLA). Biomaterials. 2005;26:5542-5551

[63] Ural E, Kesenci K, Fambri L, Migliaresi C, Piskin E. Poly(D,L-cactide/epsiloncaprolactone)/hydroxyapatite composites. Biomaterials. 2000;21:2147-2154

[64] Ang KC, Leong KF, Chua CK, Chandrasekaran M. Compressive properties and degradability of poly(epsilon-caprolatone)/hydroxyapatite composites under accelerated hydrolytic degradation. J Biomed Mater Res. A. 2007;80A:655-660

[65] Lu L, Zhang Q, Wootton D, Chiou R, Li D, Lu B, Lelkes P, Zhou J. Biocompatibility and biodegradation studies of PCL/beta-TCP bone tissue scaffold fabricated by structural porogen method. J Mater Sci: Mater Med. 2012;23:2217-2226

[66] Kim H, Knowles J, Kim H. Hydroxyapatite/poly(epsilon-caprolactone) composite coatings on hydroxyapatite porous bone scaffold for drug delivery. Biomaterials. 2004;25:1279-1287 


\section{FIGURE CAPTIONS}

Figure 1. Microstructure of polyester scaffolds before degradation (bar size: $150 \mu \mathrm{m}$ )

Figure 2. Evolution of sample weight and composition with time as determined by weighing and thermogravimetry. PCL (Blue), PLLA (green) and inorganic content (red). Error bars represent standard deviation, $N=7$. Significance $(p<0.05)$ compared to same material phase at day 0 is signaled as: (A) PLLA, (B) PCL and (C) mineral particles.

Figure 3. Evolution of sample porosity with degradation time Error bars represent standard deviation ( $N=7$ when integrity made it possible). Significance $(p<0.05)$ compared to same scaffold at day 0 is signalled as: (a) PCLb, (b) PLLAb, (A) PCLb-H and (B) PLLAb-H.

Figure 4. Microstructure of polyester scaffolds after 78 weeks of degradation (bar size: 300 $\mu \mathrm{m})$

Figure 5. $D S C$-based values of crystallinity and fusion onset temperature of $P C L(A, B)$ and PLLA (C, D) phase in the different blends

Figure 6. XRD patterns of non-degraded (unbroken line) and degraded (dotted line) samples at 78 weeks

Figure 7. Crystal size evolution with degradation time

Figure 8. Mechanical compressive properties of the scaffolds. Typical stress strain curve for scaffolds with its three zones at time zero (A) evolution of the elastic modulus with time (B) evolution of the yield strength with time (C) and evolution of the densification modulus with time. $N=7$ when integrity made it possible). Significance $(p<0.05)$ compared to same scaffold at day 0 is signalled as: (a) PCLb, (b) PLLAb, (A) PCLb-H and (B) PLLAb-H. 1

Figure 9. Evolution of molecular weight distribution with degradation time

Figure S1: Detail of sample microstructure

Figure S2: Plot of $\log \left(M_{n}\right)$ against time. Trend lines represent the linear fit. 